\title{
Perancangan Ulang Tata Letak Fasilitas Produksi UKM Eko Bubut dengan Kolaborasi Pendekatan Konvensional 5 S dan Systematic Layout Planning (SLP)
}

\author{
Alfian Rahmawan, Okka Adiyanto* \\ Program Studi Teknik Industri, Universitas Ahmad Dahlan Yogyakarta \\ *e-mail : okka.adiyanto@ie.uad.ac.id
}

\begin{abstract}
Abstrak
Pengaturan tata letak (layout) pabrik merupakan salah satu masalah yang sering dijumpai bahkan tidak dapat dihindari dalam dunia industi kecil maupun besar. Penelitian ini dilakukan di UKM Eko Bubut Yogyakarta. UKM Eko Bubut memproduksi perlengkapan makanan dari kayu. Banyaknya departemen produksi pada UKM Eko Bubut mengakibatkan are kerja tidak tersusun rapid an juga menyebabkan back tracking sehingga akan menghambat aliran produksi. Pada penelitian ini bertujuan untuk memberikan usulan tata letak produksi pada UKM Eko Bubut. Pendekatan yang dilakukan dalam mengatasi permasalahan pada UKM Eko Bubut yaitu dengan menerapkan pendekatan 5S dan metode Systematic Layout Planning (SLP). Berdasarkan hasil pengolahan data menggunakan perancangan tata letak dengan dan metode Systematic Layout Planning (SLP), maka didapatkan 5 alternatif layout dengan jarak perpindahan material dan nilai OMH yang berbeda-beda. Layout alternatif yang dipilih berdasarkan nilai jarak perpindahan dan OMH terkecil yaitu layout alternatif 5 dengan total jarak perpindahan sebesar 71,4 meter dan OMH sebesar Rp. 31.338,00. Berdasarkan evaluasi 5S maka diperlukan rak peralatan yang berguna untuk menempatkan alat-alat bantu agar tidak berserakan dan mengganggu aliran produksinya.
\end{abstract}

Kata kunci : Perancangan ulang, tata letak produksi, 5S, Systematic Layout Planning (SLP)

Abstract

Factory layout is one of the problems that often arise in the world of small and large industries. This research conducted at UKM Eko Bubut Yogyakarta. UKM Eko Bubut produces food equipment made of wood. A large number of production departments in UKM Eko Bubut causes the work area is not arranged rapidly and also causes backtracking so that it will hamper the flow of production. In this study aims to provide production layout proposals for UKM Eko Bubut. The approach taken in overcoming problems in UKM Eko Bubut is by applying the 5 S approach and the Systematic Layout Planning (SLP) method. Based on the results of data processing using the layout design with the Systematic Layout Planning (SLP) method, then obtained 5 alternative layouts with different material displacement distances and OMH values. The alternative layout was chosen based on the value of the smallest displacement distance, and $\mathrm{OMH}$ is alternative layout 5 with a total displacement distance of 71.4 meters and OMH of Rp. 31,338.00. Based on the $5 S$ evaluation, it is necessary to have a rack of equipment that is useful for placing tools to avoid scattering and disrupting the production flow.

Keywords : Re-layout, production layout, 5S, Systematic Layout Planning (SLP)

\section{PENDAHULUAN}

Pengaturan tata letak (layout) pabrik merupakan masalah yang sering dijumpai bahkan tidak dapat dihindari dalam dunia industri meskipun untuk lingkup yang lebih kecil dan sederhana, setiap industri (badan usaha) membutuhkan pengaturan tata letak (layout) pabrik yang baik agar proses produksi dapat beroperasi dengan baik. Tata letak pabrik merupakan kegiatan pengaturan tata letak, membentuk konsep serta membuat system dari produk barang maupun jasa, kegiatan tersebut dilakukan untuk mencapai perekenomian yang produktif (Choir, Arief, \& Siska, 2017). Tujuan dari penyusunan layout yaitu agar proses produksi berjalan dengan lancer dan juga untuk meningkatkan kapasitas produksi (Nelfiyanti, Rani, \& Ramadhan, 2016).

Faktor pendukung yang penting dalam kelancaran pelaksanaan suatu proses produksi adalah efisiensi waktu kerja yang optimal yang didukung dengan tata letak (layout) pabrik yang baik (Adiyanto \& Rizky Paldo, 2019). UKM Eko Bubut merupakan UKM yang bergerak di bidang kerajinan kayu. 
UKM ini membuat berbagai macam kerajinan kayu seperti perlengkapan alat makan dari kayu berupa mangkok, piring, nampan, sendok, dan lain-lain. Lantai produksi UKM Eko Bubut memiliki 10 departemen, yaitu gudang bahan baku, pengovenan, pemotongan (mesin circle), pemolaan dan pemotongan pola (mesin jigsaw), pembubutan luar, pembubutan dalam, penghalusan, pengeboran, gudang produk jadi dan setengah jadi, dan stasiun kerja finishing. Seluruh aktivitas produksi tersebut dilakukan di UKM Eko Bubut. Permasalahan yang dihadapi UKM Eko Bubut adalah pada tata letak lantai produksi yang tidak tertata rapi, dan tidak mempertimbangkan urutan proses pembuatan produk. Terdapat banyak departemen yang tidak tertata dengan baik, alat bantu / tools tidak ditata tetapi dibiarkan berserakan di area kerja. Bahan baku dan produk setengah jadi tidak tertata secara rapi dan banyak berserakan di are kerja mengakibatkan dapat mengganggu aliran material in dan out pada setiap departemen sehingga jarak material handling menjadi lebih besar, dan jarak antar departemen tidak berdekatan. Terdapat back tracking pada aliran material pembuatan produk mangkok kayu, yaitu saat bahan baku produk mangkok kayu departemen pengovenan dan kembali lagi dengan jalur yang sama menuju ke departemen pemotongan. Hal inilah yang membuat diperlukan adanya penataan ulang untuk layout lantai produksi yang digunakan dengan mempertimbangkan material handling di lantai produksi. UKM eko Bubut merupakan salah satu UKM yang menerapkan system proses system Job shop. Job Shop merupakan pembuatan produk yang tergantung pada bentuk produk dimana pesanan yang berbeda maka akan memilki urutan yang berbeda dalam membuat suatu produk tersebut (Maheswari \& Firdauzy, 2015).

Pada penelitian ini dilakukan pemecahan masalah dengan cara menggabungkan 2 metode yaitu metode $5 \mathrm{~S}$ dan juga metode Systematic Layout Planning (SLP). Pendekatan 5S digunakan untuk melakukan perencanaan layout supaya tertata rapi, ringkas, serta menciptakan kondisi kerja yang baik untuk pekerja. Metode Systematic Layout Planning (SLP) dipilih karena digunakan untuk merancang ulang layout lantai produksi dengan tujuan dapat meminimalkan ongkos material handling dengan mempertimbangkan aliran material. Penelitian dari (Anwar, Bakhtiar, S, \& Nanda, 2015; Choir et al., 2017) menyelesaikan masalah dalam menentukan layout produksi dengan cara satu metode yaitu Systematic Layout Planning (SLP). Pada penelitian (Putri \& Ismanto, 2019; Sofyan \& Syarifuddin, 2015) juga menggunakan satu pendekatan yaitu pendekatan konvensional 5S. Pada penelitian-penelitain terdahulu hanya menggunakan satu pendekatan untuk membuat usulan perbaikan layout suatu perusahaan. Tujuan penelitian ini yaitu untuk memperbaiki tata letak produksi pada UKM Eko Bubut sehingga tidak mengalami back tracking pada aliran produksinya. Selain itu penelitian ini juga bertujuan untuk menggabungkan antara 2 pendekatan konvensional 5S dan juga Systematic Layout Planning (SLP).

\section{METODE PENELITIAN}

Obyek penelitian di berada di UKM Eko Bubut Dusun Gumawang Kecamatan Patuk Kabupaten Gunung Kidul. Pemilihan objek penelitian di UKM Eko Bubut dikarenakan terdapat back tracking pada aliran material pembuatan produknya sehingga akan memperlama proses produksi dan peletakan peraltan-peraltan produksi tidak tertata rapi. Metode yang digunakan untuk menyelesaikan permasalahan yang ada di UKM Eko Bubut yaitu dengan penggabungan antara 5S dan juga menggunakan metode SLP (Systematic Layout Planning). Pada alasan dilakukan metode 5S yaitu pada metode 5S ini dapat digunakan untuk melakukan perencanaan layout supaya tertata rapi, ringkas, serta menciptakan kondisi kerja yang baik untuk pekerja. Metode Systematic Layout Planning (SLP) dipilih karena digunakan untuk merancang ulang layout lantai produksi dengan tujuan dapat meminimalkan material handling dengan mempertimbangkan aliran material. 


\section{HASIL DAN PEMBAHASAN}

\section{Metode 5S}

Pada metode 5S ini dilakukan identifikasi dan penilaian 5S di UKM eko Bubut menggunakan bantuan kuiosner yang terdiri kuisioner kebutuhan dan juga kuisioner keadaan. Pengisian kuioner dilakukan oleh semua pekerja yang ada di UKM eko Bubut. Hasil dari kuisioner kebutuhan dan keadaan dapat dilihat pada Tabel 1.

Tabel 1 hasil kuisioner metode $5 \mathrm{~S}$

\begin{tabular}{|c|c|c|c|c|}
\hline No & 5S & Kebutuhan & Keadaan & Keterangan \\
\hline 1 & Seiri (Ringkas) & A 1,36 & A $\quad-1,36$ & Perlu perbaikan \\
\hline & & B 1,45 & $-1,45$ & Perlu perbaikan \\
\hline 2 & Seiton (Rapi) & A 1,82 & -0.91 & Perlu perbaikan \\
\hline & & $\begin{array}{ll}\mathrm{B} & 1,73\end{array}$ & $-1,09$ & Perlu perbaikan \\
\hline 3 & Seiso (Resik) & 1,91 & $-1,73$ & Perlu perbaikan \\
\hline & & $\begin{array}{ll}\text { B } & 1,64\end{array}$ & $-1,64$ & Perlu perbaikan \\
\hline 4 & Seiketsu (Rawat) & 1,91 & $-0,91$ & Perlu perbaikan \\
\hline & & $\begin{array}{ll}\text { B } & 1,82\end{array}$ & $-1,45$ & Perlu perbaikan \\
\hline 5 & Shitsuke (Rajin) & 1,45 & $-0,73$ & Perlu perbaikan \\
\hline & & B 1,36 & $-0,82$ & Perlu perbaikan \\
\hline
\end{tabular}

Tabel 1 tersebut dapat dilihat bahwa seluruh prinsip 5S kebutuhan berada di bagian positif $(+)$ sedangkan keadaan berada pada bagian negatif (-). Hal ini memperlihatkan bahwa karyawan UKM. Eko Bubut yang menjadi responden kuisioner membutuhkan perbaikan dilingkungan kerja dengan pendekatan $5 \mathrm{~S}$.

\section{Metode SLP}

\subsection{Luas Departemen UKM Eko Bubut}

UKM Eko Bubut memiliki lahan produksi dengan ukuran panjang 20,5m dan lebar 16,5m dan luas total 338,25 $\mathrm{m}^{2}$. Luas departemen pada UKm Eko Bubut dapat dilihat pada Tabel 2.

Tabel 2 Luas Departemen

\begin{tabular}{|c|c|c|c|c|}
\hline \multirow[b]{2}{*}{ No } & \multirow[b]{2}{*}{ Nama Departemen } & \multicolumn{2}{|c|}{ Ukuran } & \multirow[b]{2}{*}{ Luas $\left(\right.$ meter $\left.^{2}\right)$} \\
\hline & & $\begin{array}{l}\text { Panjang } \\
\text { (meter) }\end{array}$ & $\begin{array}{l}\text { Lebar } \\
\text { (meter) }\end{array}$ & \\
\hline 1 & Gudang bahan baku & 4 & 4,5 & 18,0 \\
\hline 2 & \begin{tabular}{|l|} 
Pengovenan \\
\end{tabular} & 4,1 & 3,3 & 13,5 \\
\hline 3 & $\begin{array}{l}\text { Pemotongan (mesin } \\
\text { circle) }\end{array}$ & 2 & 4,5 & 9,0 \\
\hline 4 & $\begin{array}{l}\text { Pemolaan dan } \\
\text { pemotongan pola (mesin } \\
\text { jigsaw) }\end{array}$ & 3 & 2 & 6,0 \\
\hline 5 & Pembubutan luar & 4 & 4,5 & 18,0 \\
\hline 6 & Pembubutan dalam & 2,5 & 4,6 & 11,5 \\
\hline 7 & Penghalusan & 1,5 & 1,5 & 2,3 \\
\hline 8 & Pengeboran & 1,5 & 1,6 & 2,4 \\
\hline 9 & $\begin{array}{l}\text { Gudang produk jadi dan } \\
\text { setengah jadi }\end{array}$ & 5,5 & 12 & 66,0 \\
\hline 10 & Finishing / pengecatan & 6 & 5,5 & 33,0 \\
\hline \multicolumn{4}{|c|}{ Total } & 179,7 \\
\hline
\end{tabular}




\subsection{Aliran Material UKM Eko Bubut dan OMH}

Aliran material yang ada di UKM eko Bubut dapat dilihat pada Gambar 1 dan OMH dapat dilihat pada Tabel 3

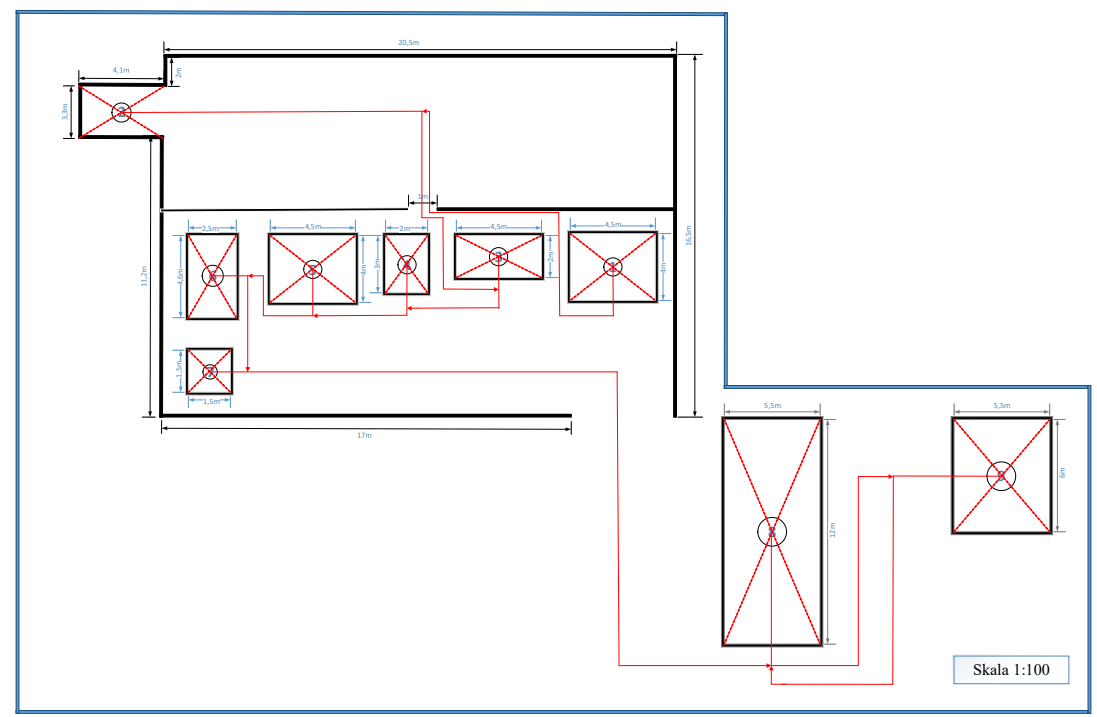

Gambar 1 Aliran Material

Tabel 3 Total OMH Layout Awal

\begin{tabular}{|c|c|c|c|c|c|c|c|}
\hline No & From & To & $\begin{array}{c}\text { Jarak } \\
\text { (meter) }\end{array}$ & Jenis Transportasi & $\begin{array}{l}\text { OMH / Meter } \\
\text { (Rp) }\end{array}$ & \multicolumn{2}{|c|}{ Total } \\
\hline 1 & Gudang bahan baku & Pengovenan & 14,8 & \multirow[b]{2}{*}{ manusia + Gerobak } & \multirow[b]{2}{*}{2000} & $\mathrm{Rp}$ & 29.600 \\
\hline 2 & Pengovenan & $\begin{array}{l}\text { Pemotongan (mesin } \\
\text { circle) }\end{array}$ & 13,8 & & & $\mathrm{Rp}$ & 27.600 \\
\hline 3 & $\begin{array}{l}\text { Pemotongan (mesin } \\
\text { circle) }\end{array}$ & $\begin{array}{l}\text { Pemolaan dan } \\
\text { pemotongan pola } \\
(\text { mesin jigsaw }) \\
\end{array}$ & 2,7 & \multirow{7}{*}{ manusia } & \multirow{7}{*}{150} & $\mathrm{Rp}$ & 405 \\
\hline 4 & $\begin{array}{l}\text { Pemolaan dan } \\
\text { pemotongan pola (mesin } \\
\text { jigsaw) }\end{array}$ & Pembubutan luar & 1,9 & & & $\mathrm{Rp}$ & 285 \\
\hline 5 & Pembubutan luar & Pembubutan dalam & 2,6 & & & $\mathrm{Rp}$ & 390 \\
\hline 6 & Pembubutan dalam & Penghalusan & 2,7 & & & $\mathrm{Rp}$ & 405 \\
\hline 7 & Penghalusan & $\begin{array}{l}\text { Gudang produk jadi } \\
\text { dan setengah jadi }\end{array}$ & 14,02 & & & $\mathrm{Rp}$ & 2.103 \\
\hline 8 & $\begin{array}{l}\text { Gudang produk jadi dan } \\
\text { setengah jadi }\end{array}$ & $\begin{array}{l}\text { Finishing / } \\
\text { pengecatan }\end{array}$ & 18 & & & $\mathrm{Rp}$ & 2.700 \\
\hline 9 & Finishing / pengecatan & $\begin{array}{l}\text { Gudang produk jadi } \\
\text { dan setengah jadi }\end{array}$ & 18 & & & $\mathrm{Rp}$ & 2.700 \\
\hline & Total & & 88,52 & $\mathrm{To}$ & & $\mathrm{Rp}$ & 66.188 \\
\hline
\end{tabular}

\subsection{Layout Usulan}

Perancangan tata letak fasilitas dengan metode Systematic Layout Planning (SLP) menghasilkan layout alternatif dengan jarak perpindahan material terpendek dan nilai ongkos material handling $(\mathrm{OMH})$ yang terkecil. Berdasarkan hasil perhitungan maka didaptkan 5 alternatif yang sesuai dengan keadaan di UKM Eko Bubut .

\subsubsection{Layout 1}

Berdasarkan hasil perhitungan, layout usulan 1 memiliki jarak perpindahan material sebesar 88, 83,5 m dan memiliki Ongkos Material Handling (OMH) sebesar Rp 38.703,00 per hari. Hasil perhitungan dan juga layout pada usulan 1 dapat dilihat pada Gambar 2. 

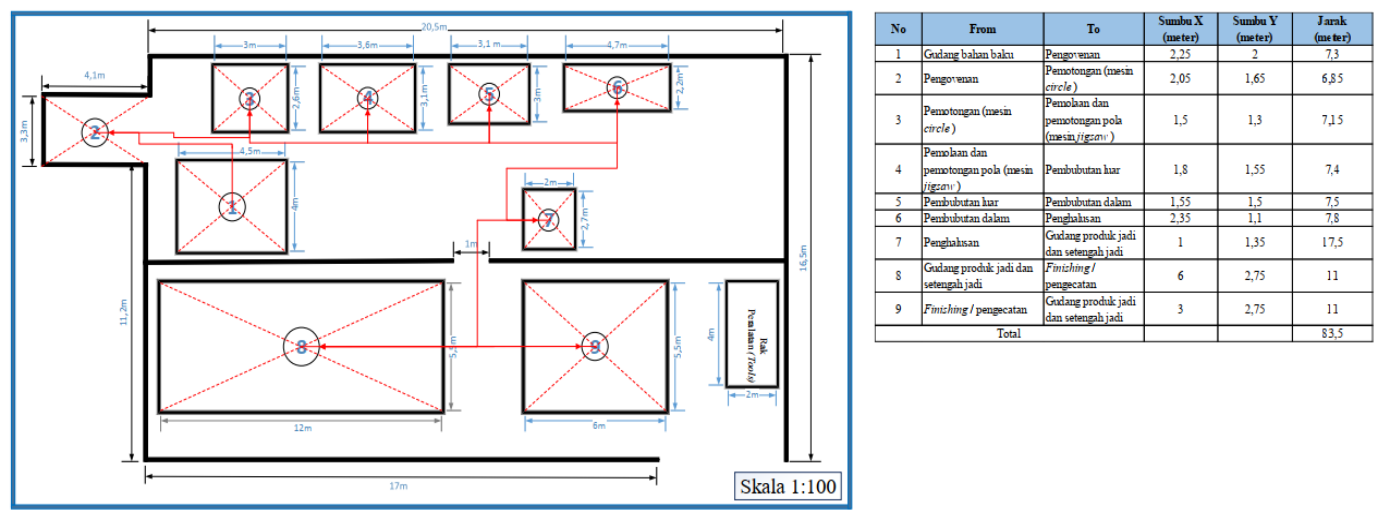

Gambar 2 Layout usulan 1

\subsubsection{Layout 2}

Pada Gambar 3 merupakan layout usulan ke 2. Berdasarkan layout usulan ke 2 tersebut maka akan didapatkan jarak perpindahan material sebesar 81,25 meter dan memiliki Ongkos material handling sebesar Rp 38.365,00 per hari.
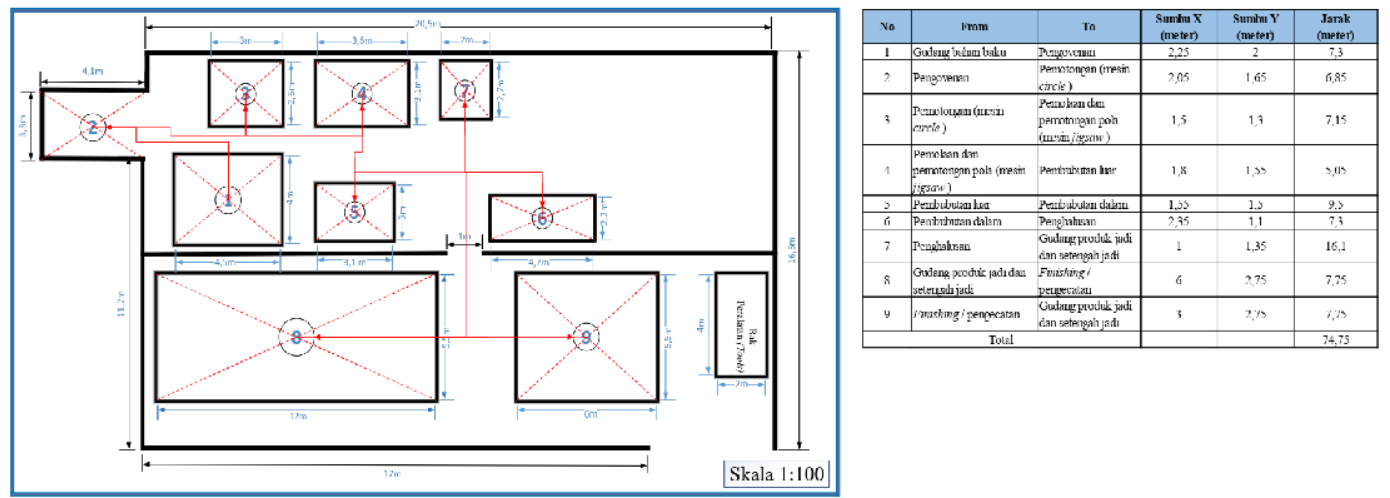

Gambar 3 Layout usulan 2

\subsubsection{Layout 3}

Usulan Layout ke 3 memiliki jarak perpindahan material sesear 69,95 meter dan nilai OMH sebesar Rp 36.670,00. Perhitungan tersebut sesaui dengan Gambar 4.
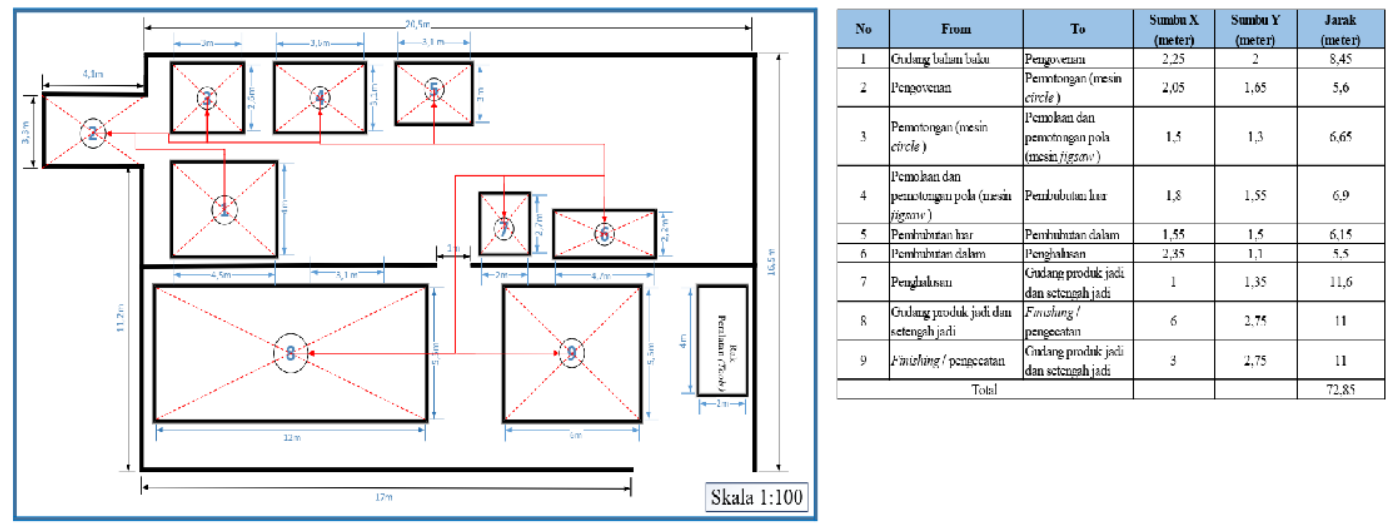

Gambar 4 Layout usulan 3 


\subsubsection{Layout 4}

Berdasarkan Gambar 5 didapatkan jarak perpindahan material sebesar 72,55 meter dan memiliki OMH sebesar Rp 33.823,00
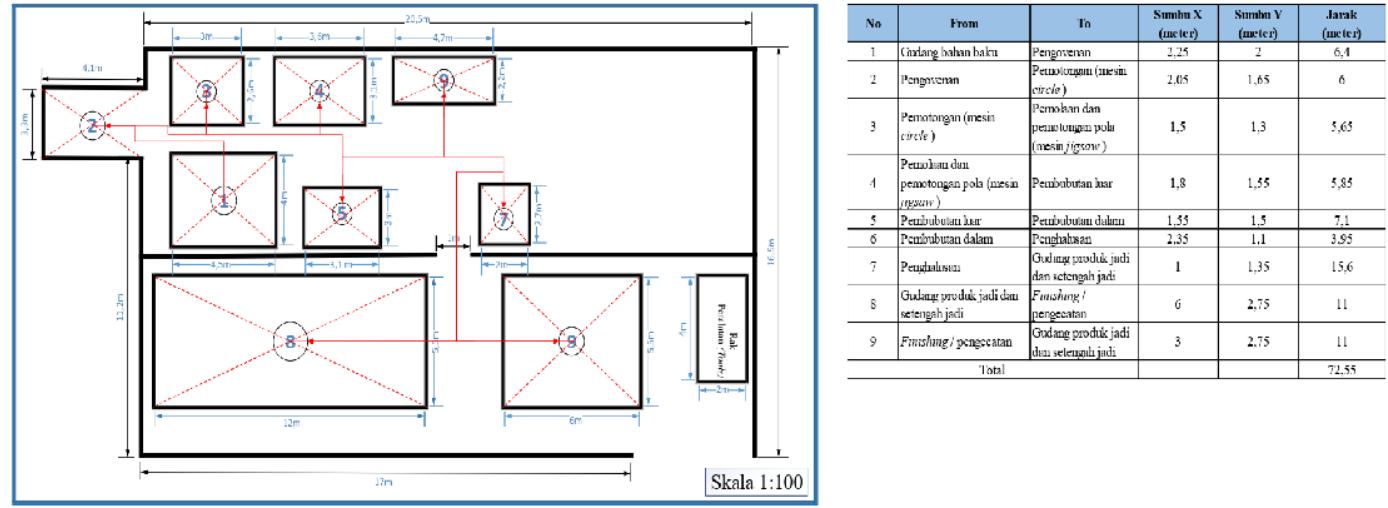

Gambar 5 Layout usulan 4

\subsubsection{Layout 5}

Usulan alternative 5 Gambar 6 memiliki jarak perpindahan sebesar 74,4 meter dan memiliki OMH sebesar Rp 37.338,00 per hari.
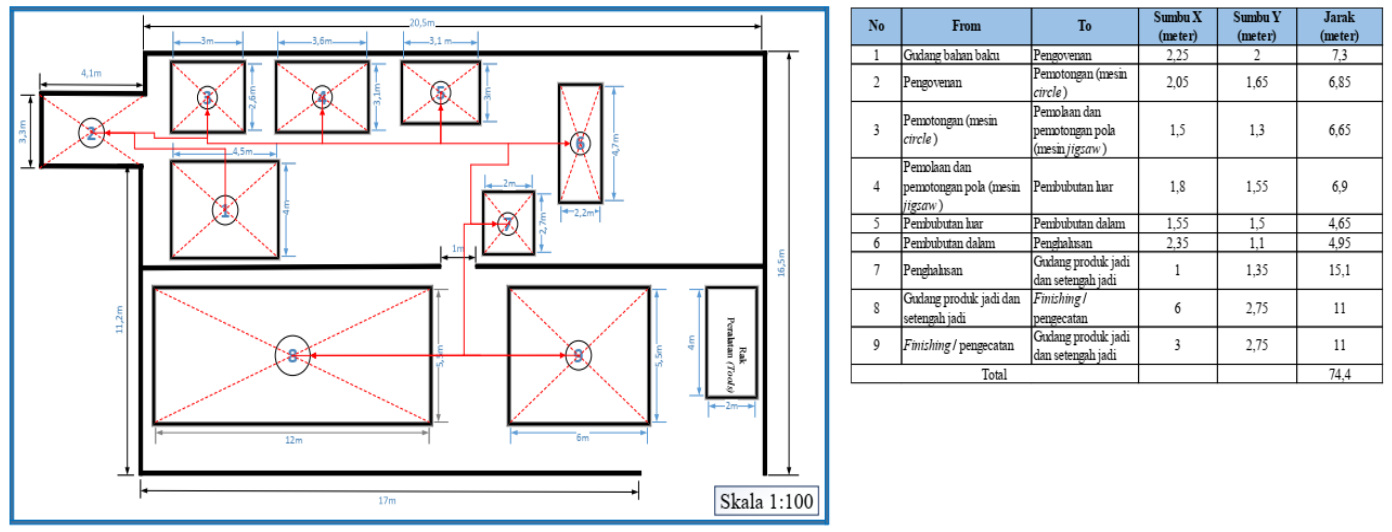

Gambar 6 Layout usulan 5

\subsection{Perbandingan Usulan Layout}

Usulan layout tersbut apabila dibuat garfik maka akan terlihat seperti pada Gambar 7 dan juga Gambar 8 . 


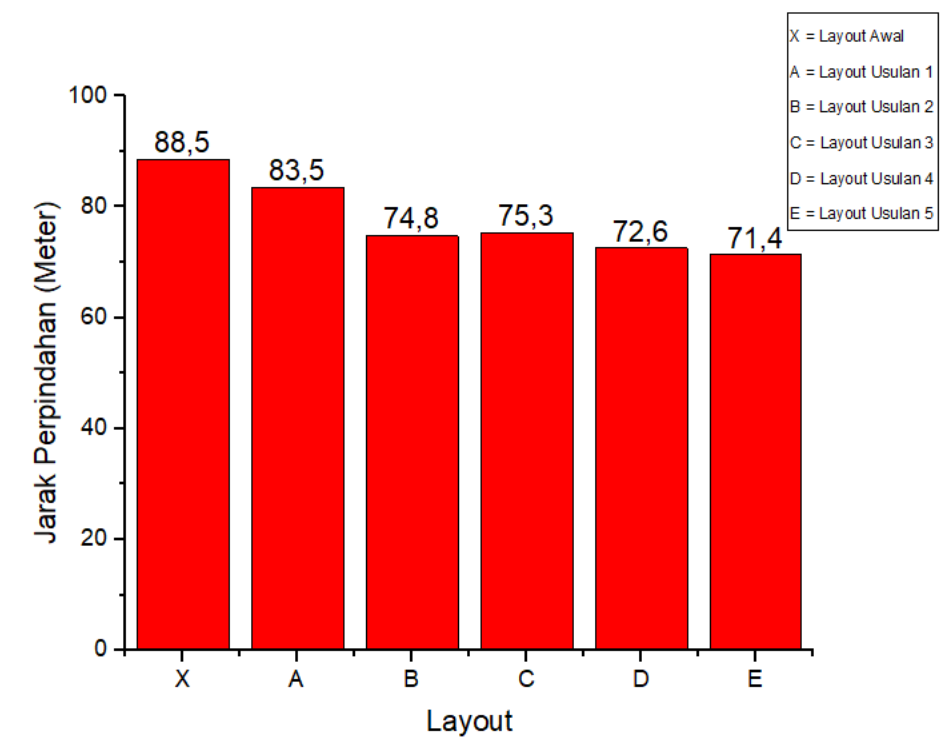

Gambar 7 Perbandingan Perpindahan Jarak

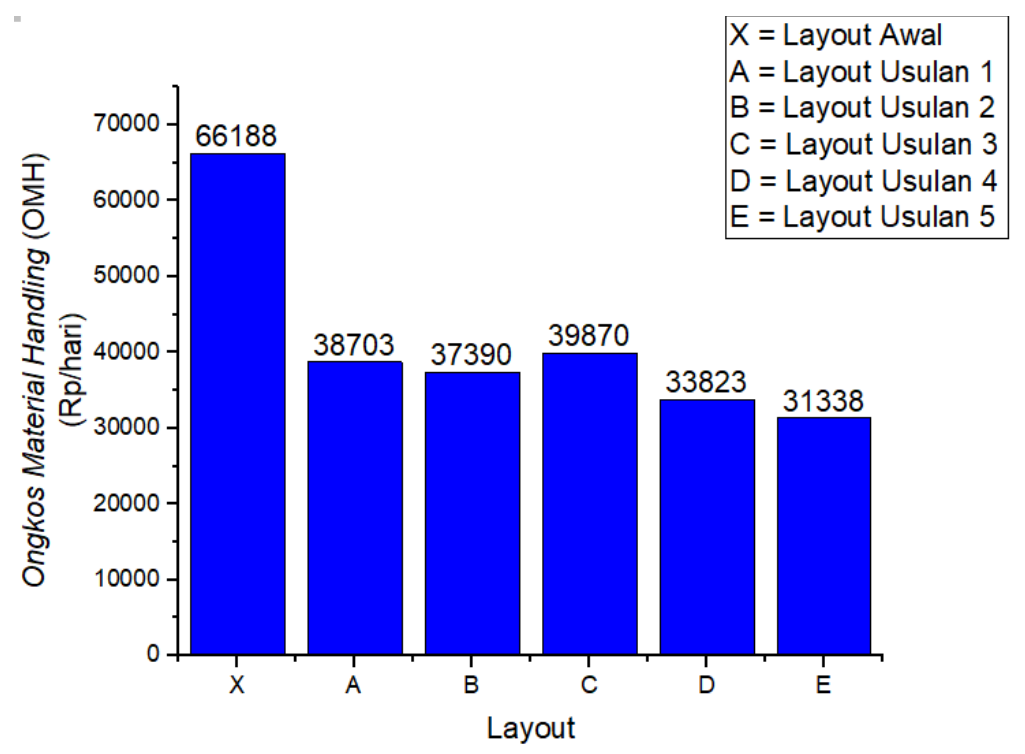

Gambar 8 Perbandingan $\mathrm{OMH}$

\section{Layout Terpilih}

Maka hasil dari pengolahan data dengan metode Systematic Layout Planning (SLP) dipilih layout alternatif 5 (Gambar 9) memiliki jarak perpindahan material sebesar 71,4 meter dan ongkos material handling (OMH) sebesar Rp. 31.338.- per hari pada Tabel 4. 


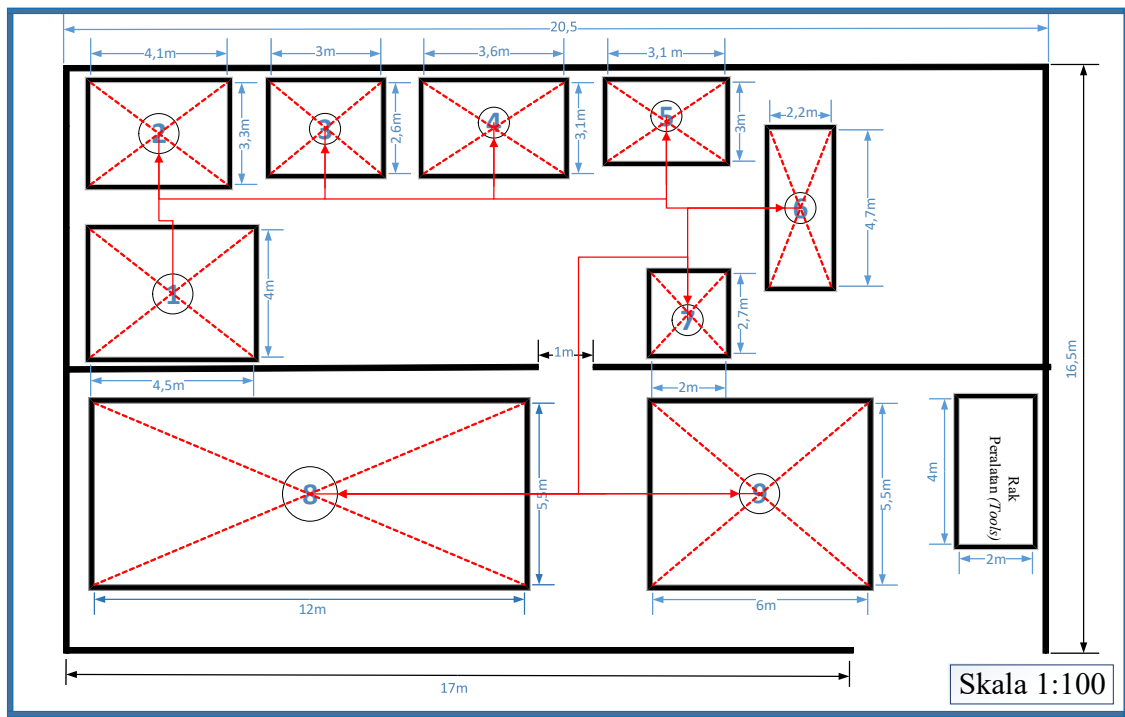

\begin{tabular}{|c|c|c|}
\hline No & From & To \\
\hline 1 & Gudang bahan baku & Pengovenan \\
\hline 2 & Pengovenan & $\begin{array}{l}\text { Pemotongan (me } \\
\text { circle) }\end{array}$ \\
\hline 3 & $\begin{array}{l}\text { Pemotongan (mesin } \\
\text { circle) }\end{array}$ & \begin{tabular}{|l}
$\begin{array}{l}\text { Pemolaan dan } \\
\text { pemotongan pola } \\
(\text { mesin jigsaw })\end{array}$ \\
\end{tabular} \\
\hline 4 & $\begin{array}{l}\begin{array}{l}\text { Pemolaan dan } \\
\text { pemotongan pola (mesin } \\
\text { jigsaw) }\end{array} \\
\end{array}$ & Pembubutan luar \\
\hline 5 & Pembubutan luar & Pembubutan dala \\
\hline 6 & Pembubutan dalam & Penghalusan \\
\hline 7 & Penghalusan & $\begin{array}{l}\text { Gudang produk } \mathrm{j} \\
\text { dan setengah jad: }\end{array}$ \\
\hline 8 & $\begin{array}{l}\text { Gudang produk jadi dan } \\
\text { setengah jadi }\end{array}$ & $\begin{array}{l}\text { Finishing/ } \\
\text { pengecatan }\end{array}$ \\
\hline 9 & Finishing / pengecatan & $\begin{array}{l}\text { Gudang produk } \mathrm{j} \\
\text { dan setengah jad: }\end{array}$ \\
\hline \\
\hline
\end{tabular}

Gambar 9 Layout Alternatif 5

Tabel 4 OMH Layout Usulan 5

\begin{tabular}{|c|c|c|c|c|c|c|c|c|}
\hline No & From & To & $\begin{array}{c}\text { Sumbu X } \\
\text { (meter) }\end{array}$ & $\begin{array}{c}\text { Sumbu Y } \\
\text { (meter) }\end{array}$ & $\begin{array}{c}\text { Jarak } \\
\text { (meter) }\end{array}$ & Jenis Transportasi & $\begin{array}{l}\text { OMH / } \\
\text { Meter } \\
\end{array}$ & Total \\
\hline 1 & Gudang bahan baku & Pengovenan & 2,25 & 2 & 4,15 & \multirow[b]{2}{*}{ manusia + Gerobak } & \multirow[b]{2}{*}{2000} & Rp $\quad 8.300$ \\
\hline 2 & Pengovenan & $\begin{array}{l}\text { Pemotongan (mesin } \\
\text { circle) }\end{array}$ & 2,05 & 1,65 & 7 & & & Rp 14.000 \\
\hline 3 & $\begin{array}{l}\text { Pemotongan (mesin } \\
\text { circle) }\end{array}$ & $\begin{array}{l}\text { Pemolaan dan } \\
\text { pemotongan pola } \\
(\text { mesin jigsaw })\end{array}$ & 1,5 & 1,3 & 6,65 & \multirow{7}{*}{ manusia } & \multirow{7}{*}{150} & 998 \\
\hline 4 & $\begin{array}{l}\text { Pemolaan dan } \\
\text { pemotongan pola (mesin } \\
\text { jigsaw) }\end{array}$ & Pembubutan luar & 1,8 & 1,55 & 6,9 & & & $\mathrm{Rp} \quad 1.035$ \\
\hline 5 & Pembubutan luar & Pembubutan dalam & 1,55 & 1,5 & 4,65 & & & Rp $\quad 698$ \\
\hline 6 & Pembubutan dalam & Penghalusan & 2,35 & 1,1 & 4,95 & & & Rp 743 \\
\hline 7 & Penghalusan & $\begin{array}{l}\text { Gudang produk jadi } \\
\text { dan setengah jadi }\end{array}$ & 1 & 1,35 & 15,1 & & & Rp 2.265 \\
\hline 8 & $\begin{array}{l}\text { Gudang produk jadi dan } \\
\text { setengah jadi }\end{array}$ & $\begin{array}{l}\text { Finishing / } \\
\text { pengecatan }\end{array}$ & 6 & 2,75 & 11 & & & Rp $\quad 1.650$ \\
\hline 9 & Finishing / pengecatan & $\begin{array}{l}\text { Gudang produk jadi } \\
\text { dan setengah jadi }\end{array}$ & 3 & 2,75 & 11 & & & Rp $\quad 1.650$ \\
\hline \multicolumn{3}{|c|}{ Total } & & & 71,4 & \multicolumn{2}{|l|}{ Total } & Rp 31.338 \\
\hline
\end{tabular}

Berdasarkan hasil pemilihan alternatif 5 tersebut maka dapat semakin pendek jarak antar departemen maka total $\mathrm{OMH}$ akan menjadi semakin kecil. Hal ini menandakan bahwa perancngan ulang fasilitas produksi akan mengakibatkan peningkatan produktivitas (Murnawan, Eka, \& Karunia, 2018). Pada penggunaan metode 5S ini akan mengakibatkan tata letak produksi menjadi lebih rapi hal ini sesuai dengan penelitian yang sudah dilakukan oleh (Sofyan \& Syarifuddin, 2015).

\section{KESIMPULAN}

Berdasarkan hasil penelitian yang sudah dilakukan maka didapatkan bahwa penggabungan 2 metode antara 5S dan juga metode SLP menjadi lebih optimal dalam menentukan perancangan ulang suatu tata letak fasilitas produksi. Berdasrakna hasil SLP maka menghasilkan 5 layout alternatif dengan perpindahan jarak material dan ongkos material handling yang lebih kecil dari pada layout awal milik 
UKM Eko Bubut. Layout alternatif 5 memiliki jarak perpindahan material sebesar 71,4 meter dan ongkos material handling (OMH) sebesar Rp. 31.338.- per hari. Selain itu, rekomendasi yang diberikan dengan pendekatan 5S (Seiri, Seiton, Seiso, Seiketsu, Shitsuke) adalah pemberian rak peralatan (tools) yang berguna untuk menempatkan alat-alat bantu supaya tidak berserakan di departemen yang dapat mengganggu aliran material dan dapat menimbulkan bahaya kecelakaan kerja.

\section{DAFTAR PUSTAKA}

Adiyanto, O., \& Rizky Paldo, M. (2019). Perancangan Tata Letak Fasilitas Produksi UKM Eko Bubut Menggunakan Metode Automated Layout Design Program (ALDEP). Teknoin, 25(2), 66-79.

Anwar, Bakhtiar, S, \& Nanda, R. (2015). Usulan Perbaikan Tata Letak Pabrik dengan Menggunakan Systematic Layout Planning ( SLP) di CV . Arasco Bireuen. Miej, 4(2), 4-10.

Choir, M., Arief, D. S., \& Siska, M. (2017). Desain Ulang Tata Letak Fasilitas Produksi Menggunakan Metode Systematic Layout Planning Pada Pabrik Kelapa Sawit Sungai Pagar. Jurnal Fteknik, 4(1), 1.

Maheswari, H., \& Firdauzy, A. D. (2015). Evaluasi Tata Letak Fasilitas Produksi Untuk Meningkatkan Efisiensi Kerja Pada Pt. Nusa Multilaksana. Jurnal Ilmiah Manajemen Dan Bisnis, 1(3).

Murnawan, H., Eka, P., \& Karunia, D. (2018). Perancangan Ulang Fasilitas Dan Ruang Produksi Untuk Meningkatkan Output Produksi. Jurnal Teknik Industri, 19(2), 157-165.

Nelfiyanti, Rani, A. M., \& Ramadhan, A. I. (2016). Perancangan Sistem Informasi dan Tata Letak Fasilitas Produksi Tas CV. Banua dengan Menggunakan Algoritma CORELAP. Seminar Nasional Sains Dan Teknologi, (November), 1-6.

Putri, R. eriani, \& Ismanto, W. (2019). Pengaruh Perancangan Ulang Tata Letak Fasilitas di Area Operasional Kerja Berbasis 5S untuk pengajuan Modal Usaha. Dimensi, 8(1), 71-89.

Sofyan, D. K., \& Syarifuddin, S. (2015). Perancangan Ulang Tata Letak Fasilitas dengan Menggunakan Metode Konvensional Berbasis 5s (Seiri, Seiton, Seiso, Seiketsu dan Shitsuke). Teknovasi, 2(2), $27-41$. 